\title{
CULTURA E HIBRIDISMO: ASPECTOS PSICOSSOCIAIS DA IDENTIDADE CULTURAL CONTEMPORÂNEA
}

DOI: $10.48075 / R I . V 2212.24988$

Paulo Victor Poncio de Oliveira ${ }^{1}$

RESUMO: O presente artigo possui como objetivo identificar os fundamentos e analisar os conceitos de cultura híbrida e hibridismo, principalmente a história social e cultural das sociedades contemporâneas. Uma análise utilizada como fontes de publicações acadêmicas na globalização cultural, mundialização, antropologia, psicologia social e hibridismo. A escolha das fontes utilizadas, portanto, justifica por serem esses fatores importantes de análise da questão cultural, constituídos por essa série de estudos em meio privilegiado para análises de informações fundamentais sobre como concepções de hibridismo e toda a organização histórica e cultural. das sociedades pós-modernas. Uma perspectiva de análise da pesquisa que parte da ideia de identidades encontradas num intrínseco tecido estrutural paradoxo quando se mostra como percepções de hibridismo e difusão de fronteiras entre as diferentes sociedades. $O$ desafio baseia-se na análise da complexidade da psicologia social envolvida nas concepções de cultura e pós-modernidade.

Palavras-chave: Hibridismo cultural; Psicologia social; pós-modernidade.

\section{CULTURE AND HYBRIDISM: PSYCHOSOCIAL ASPECTS OF CONTEMPORARY CULTURAL IDENTITY}

ABSTRACT: The objective of this study was to implement and evaluate a program of parental skills in families in noncompliance with conditionalities with the Bolsa Família Program, due to school dropout among adolescent children and high incidence of family conflict. The study design was the case study. Two families participated, evaluated through the Inventory of Parenting Styles - IEP in the pre and post intervention condition and in the three months follow up. The intervention was performed at home and consisted of eight sessions in which it was discussed: self-control and stress management; positive and negative parenting practices; contingency analysis; limits and discipline. The results showed that in both participating families there was an increase in the behavioral repertoire in the mothers regarding the establishment and compliance of rules, the establishment of dialogue as a form of negotiation and resolution of conflicts, the strengthening of bonds through affection, joint activities and reinforcement positive. The program proved to be effective in developing parenting skills in participating families.

Key words: Parental education; Applied behavior analysis; Public politics; Family.

\footnotetext{
${ }^{1}$ Mestre em Educação, Especialista em Psicologia Social, Graduado em Gestão Pública. Universidade Federal da Integração Latino-Americana - UNILA. Foz do Iguaçu - Paraná. E-mail: victormanfredine@gmail.com.
} 


\title{
INTRODUÇÃO
}

\author{
"Entre las formas que van hacia la sierpe \\ Entre las formas que van hacia el cristal \\ Dejaré caer mis cabellos..." \\ Federico García Lorca, Poeta en Nueva York, 1940.
}

Quaisquer pesquisas que se aprofundem em analisar a história social do hibridismo cultural passará em algum momento pela discussão dos conceitos pragmáticos, ontológicos e epistemológicos, que ajudam a definir o que de fato acontece durante os processos de relacionamento social e cultural dos povos. Contudo, esse debate conceitual tende a se defrontar com o paradoxo que surge da importante relação entre hibridismo e pósmodernidade, visto que ao menos pragmaticamente, a defesa da difusão de culturas heterogêneas tende a dificultar a concepção da identidade individual e social. Têm-se aqui o início de uma ampla e às vezes hostil discussão acerca da relação entre o hibridismo e a homologia social, cujos anseios estruturais nem sempre são os mesmos.

No que tange a um debate acadêmico acerca de fatos sociais culturais é de suma importância a assimilação teórica de um aporte de conceitos vinculados à globalização intensificada no mundo a partir das últimas décadas. Trata-se de um conjunto tão grande de transformações sociais, que tal processo acabou não só por modificar os esteios culturais das sociedades, como também foi capaz de se refletir enquanto resultado de uma infinda gama de alterações nas percepções até então utilizadas para se explicar o mundo. Nesse contexto, a globalização surge para ser influenciada e também para influenciar a cultura social.

Em termos analíticos, ao tempo em que nenhuma sociedade nacional se constrói sem influência dessa globalização cultural, não há um debate isento acerca da validação, quando da reflexão sob os conceitos de identidade. A organização social necessita, historicamente, de um ambiente propício para a construção de sua própria estrutura social e cultural, de modo que quaisquer movimentos de hibridismo, anexação cultural ou mesmo adaptação, nem sempre são bem recepcionados pelos diversos atores sociais. Assim, a formação da identidade nacional emerge em um contexto rico de transformação, ao tempo em que se depara com a volatilização de seus processos, o que de fato deve ser refletido sob todos os ângulos. 
No contexto individual, as relações construídas entre os conceitos de hibridismo e identidade tendem a se acirrar ainda mais, pois o processo de formação cultural passa a se organizar dentro de uma lógica relativa à unicidade e ao equilíbrio pessoal, além de perpassar o contexto sentimental e emotivo, que permite o reconhecimento social no desenvolvimento psíquico, onde agem elementos psicológicos e comunitários. Assim, a cultura, enquanto agente social intrínseca à visão individual, assume um papel de fundamental relevância na própria construção da identidade, o que nesse contexto, vincula uma situação estrutural de reciprocidade, que deve ser peremptoriamente estudada.

Assim, a análise aprofundada do hibridismo cultural surgido com a globalização e intimamente relacionado às concepções de identidade, muito marcantes nos estudos conceituais da pós-modernidade, se dão com foco no campo acadêmico da psicologia social, que se caracteriza pela investigação do comportamento dos indivíduos no que tange à sua própria capacidade de influenciar e, principalmente, de ser influenciado socialmente. Tal influência histórica e social surge da aquisição da linguagem, mas ultrapassa o contexto meramente semiótico, ao estudar a relação fundamental que se constrói invariavelmente entre o indivíduo e a sociedade do qual faz parte.

A pesquisa em história da cultura social não deve apenas se comprometer com a análise dos movimentos culturais conectados com a vertente criativa e imaginária da capacidade humana, pois nem só de fatos culturais deve se fundamentar uma teoria histórica. Nesse contexto, temos que até a industrialização calcada no processo de globalização econômica das mais diversas sociedades exerce um papel essencial no crescimento da difusão de hábitos culturais, e por isso é que a função do pesquisador desafia uma lógica social que deve inclusive adentrar na percepção que se tem do papel dos meios de comunicação de massa perante a disseminação do que a sociedade considera ser cultura.

É nessa linha de reflexão que podemos perceber um interessante contraste na da evolução do capitalismo internacional. Até meados do século XX, as interações socioeconômicas poderiam ser entendidas como ocorrendo, em linhas gerais, por meio de fluxos de comércio, produção, consumo e investimento colocados sob a regulação dos Estados. Por sua vez, no contexto de uma realidade definida como globalizada, a lógica produtiva passa a ser organizada em uma cadeia transfronteiriça, que escapa, em grande parte, aos poderes regulatórios nacionais e internacionais impostos por órgãos interestatais criados para esse fim - tais como o Gatt e o Fundo Monetário Internacional. (IORIS, 2010, p. 2). 
Ademais, toda essa reflexão deve considerar as percepções que advém da pósmodernidade, que identifica um indivíduo definitivamente em crise em virtude dos anseios que a própria modernidade não deu conta de explicar. Assim, hibridismo, identidade e globalização se deparam com um cenário fluido e complexo onde a cultura tradicional começa a perder suas bases de integridade para um momento social de fluidez das fronteiras, que agora se mostram cada vez mais difusas. A partir de então, todo processo de análise precisa partir de um estudo aprofundado das concepções contemporâneas de psicologia e cultura social. E é o que esse trabalho se compromete a fazer a partir de agora.

\section{CULTURA HÍBRIDA: CONCEPÇÕES CONTEMPORÂNEAS}

Cultura é um conceito que há muito tempo tem sido estudado por intelectuais e cientistas das mais diversas áreas da antropologia, sociologia e até da psicologia social. Os estudos que mais se aproximaram de uma resposta conclusiva se detiveram na análise histórica dos grupos sociais e civilizações, partindo de um ponto de partida também cultural, visto que não há como fugir à percepção de pertencimento que se constrói desde o nascimento do indivíduo. Assim, é preciso que a cultura seja amplamente considerada como um processo que abrange todos os tipos de arte humana, e para além disso, que percebe e representa o conjunto de todos os modos de vida e comportamentos sociais.

No que tange aos primeiros reconhecimentos culturais tradicionais, abre-se aqui um debate em relação ao sentimento de pertencimento que tende a relacionar fortemente o indivíduo e sua comunidade à forma como os processos sociais foram se construindo com o passar do tempo. No contexto, tais processos de desenvolvimento de conhecimentos históricos e sociais vão se ligando e se conectando, de tal forma criam-se outras possibilidades de aprendizagens e fortalecimento cultural que antes não existiam - amplia-se o universo científico e educacional, o que de fato promove a construção e o fortalecimento do sentimento de pertencimento às diversidades culturais locais e regionais.

Podemos afirmar que o sentimento de pertencimento implica em olhar e reconhecer-se. Provoca ainda pensar em si mesmo como integrante de uma sociedade que atribui símbolos e valores éticos e morais, o que destaca características culturais. O sentimento manifestado pelos sujeitos sociais 
acerca do ambiente em que vivem carrega as singularidades de sua formação e encerra circunstâncias emocionais, muitas vezes, apenas vividas ali. A referida manifestação é relevante para a vida social, um sentimento que deve ser levado em consideração nos estudos e análises de comunidades. (FREITAS apud CARDOSO et al., 2017, p. 89).

Em relação a discussão acerca de eventuais processos de homogeneidade cultural é preciso observar que não há, de fato, investigações teóricas que admitam uma tendência positiva definitiva à esse lócus de pesquisa. Todavia, todo trabalho deve investigar os preconceitos advindos dessa abordagem histórica e cultural, visto que se a homogeneidade pode ser considerada adequada para algumas sociedades, para outras não há indícios que baseiem tal percepção. Ao mais, a mistura de processos sociais sem uma devida análise antropológica não se sustenta, ao passo em que no máximo trará para o campo de pesquisa um olhar incompleto e errôneo. É necessário que se entenda o debate dos estudos interculturais para um contexto global, que identifique e considere todas as uniformidades culturais nacionais.

Convém destacar que a importância da diversidade cultural deve prevalecer no debate social que fomenta as diferenças entre as sociedades, visto que nenhuma civilização organizada conseguiu obter níveis consideráveis de desenvolvimento intelectual e humano sem estabelecer relações com outras civilizações. Todavia, é relevante que se respeite as diversas culturas, sempre considerando a não-violação da dignidade humana e a percepção de interesses escusos que porventura venham a mascarar interesses de relativismo cultural ${ }^{2}$. Contudo, as sociedades e seus indivíduos possuem culturas e visões de mundo diferentes, por isso a importância de estudos culturais reforçarem os perigos que essas diferenças podem vir a causar estruturalmente. Tais processos tendem a considerar os modos de vida e comportamentos sociais de determinados grupos dominantes, mais "corretos" do que os dos demais, o que desvaloriza a cultura dos que estão fora dos padrões estabelecidos e que pode acabar reforçando o processo do etnocentrismo cultural $^{3}$.

\footnotetext{
${ }^{2}$ Segundo os estudos de Melville Jean Herskovits, antropólogo americano, o relativismo cultural é definido como a ideia de que qualquer item do comportamento deve primeiro ser julgado em relação ao seu lugar na estrutura única da cultura em que ocorre e em termos do sistema particular de valores daquela cultura. Sendo assim, quaisquer itens culturais só devem ser julgados dentro do seu próprio contexto de surgimento.

${ }^{3}$ De acordo com Everardo Guimarães Rocha, sociólogo brasileiro, etnocentrismo é um processo onde o nosso próprio grupo é tomado como centro de tudo e todos os outros são pensados e sentidos através dos nossos valores, nossos modelos e nossas próprias definições conceituais.
} 
A interculturalidade conduz uma discussão em torno das formas de reconhecimento das identidades culturais. A fim de solucionar conflitos, destaca-se que a interculturalidade é uma categoria que permite dar conta do modo de contato que pode ser simétrico ou assimétrico... À vista do exposto, afirmamos que o interculturalismo vem a motivar e alimentar a possibilidade de vivermos num mundo plural, mas com o igual respeito aos direitos humanos. O exercício do diálogo intercultural nos faz pensar que também o respeito à alteridade é algo a ser aprendido, adquirido. Quem sabe assim chegará o dia em que as distintas culturas dialogarão efetivamente e conviverão em harmonia, sem opressão sobre aquilo que todos trazemos dentro de nós: nossa própria humanidade. (ASTRAIN; DAVIES \& NUNES et al., 2015, p. 5).

No contexto da globalização, é um desafio compreender o comportamento e as mudanças da cultura nas sociedades, entender como elas se expressam no ambiente espaço social cada vez mais interligado. Apesar disso, é fundamental compreender a função e o importante papel que o processo de globalização traz para este cenário, pois o estabelecimento dessa conexão global passou a facilitar a comunicação, e com isso, a transmissão dos valores culturais. Dessa forma, o mundo contemporâneo passou a observar que diversas e diferentes culturas passam a poder interagir sem a necessidade de uma integração territorial, o que de fato simbolizou um avanço gigantesco no aspecto positivo do hibridismo cultural.

Para além disso, surge com a globalização a possibilidade de estruturação de um processo global de cultura itinerante, que, de todo modo, torna possível que um indivíduo de determinada e específica sociedade possa conhecer e utilizar de produtos e/ou serviços produzidos por um povo com o qual ele não tem relação direta. Assim, a culinária, como exemplo de processo cultural híbrido, por exemplo, pode dar conta de produzir pratos regionais, assim como pode assimilar compilações oriundas de outras regiões e países - o consumidor, agente cultural, nesse caso, escolhe entre consumir um produto típico, híbrido ou mesmo fabricado por empresas multinacionais.

A Globalização não é um processo de supressão das diferenças culturais. Se analisarmos as paisagens culturais atuais, verificaremos que o processo de Globalização cultural é complexo e mesmo contraditório. A dinâmica da globalização produz, simultaneamente, mais uniformidade e mais diversidade... Por outro lado, as ciências sociais há muito vêm sublinhando e demonstrando que os consumidores não são sujeitos passivos, pelo contrário, são sujeitos ativos: nas suas práticas de consumo, apropriam-se dos conteúdos e frequentemente reinventam-nos investindo neles 
elementos próprios das suas respectivas culturas (modos de ser, fazer e entender). (CAMPOS \& CANAVEZES, 2007, p. 75-76).

Ao mais, os processos psicossociais que surgiram ou se intensificaram junto com a globalização dos meios de produção e de comunicação de massa se tornam cada vez mais irreversíveis, ao ponto de que não é mais possível, se é que em algum momento isso foi possível, entender a existência de uma sociedade sem considerar sua relação com todas as demais comunidades ao seu entorno. O hibridismo cultural surge para relacionar de forma equilibrada todos os processos históricos e sociais das comunidades globais, sua heterogeneidade, a importância das trocas de experiências entre os povos, considerando, em última análise, a impossibilidade real da existência de uma cultura pura.

\section{A PSICOLOGIA SOCIAL DA IDEOLOGIA IDENTITÁRIA}

Uma abordagem repleta de significados no que tange à constituição do tecido social deve passar, indubitavelmente, pela análise dos processos de construção das identidades, que se definem por meio do convívio social com a família e o contexto social. Isso se baseia no fato de que qualquer sujeito é produzido como um efeito do discurso formador - sendo que ao mesmo tempo atua nesse discurso, que é estruturado a partir de formações discursivas específicas - não possuindo uma existência única e absolutamente própria. Dessa forma, a idealização da identidade individual se constrói desde o nascimento, e todos os processos culturais compartilham a responsabilidade de influenciar diretamente tal indivíduo.

Já no contexto do conceito de família e comunidade, temos que os grupos familiares existentes na contemporaneidade podem ser percebidos como frutos do processo histórico, em que os padrões, tradições e indigências da sociedade, gerados ao longo do contexto histórico, ajudaram a adaptá-los, assim como as funções de cada membro da família, que vem, inclusive, modificando sua dinâmica de formação ${ }^{4}$.

Um importante aspecto que se relaciona à própria existência social de um indivíduo é a necessidade de construção dessa identidade cultural, uma noção de contexto e conjunto

\footnotetext{
${ }^{4}$ Segundo as pesquisas de Dalva Azevedo Gueiros, socióloga brasileira, a transformação do modelo familiar patriarcal derivou do progresso da globalização e industrialização em que tal família é modificada pela família conjugal moderna nuclear, típica do mundo urbano e reduzida, muitas vezes, na qual o relacionamento conjugal já não possui mais em seu âmago a manutenção de interesses políticos comuns.
}

Ideação. Revista do Centro de Educação, Letras e Saúde. v. 22, n², 2020. e-ISSN: 1982-3010. 
que o leve a fazer concentrar em uma imagem de si mesmo as muitas facetas do seu próprio comportamento, as muitas funções que ele representa em diversos campos da sua experiência social. Assim, continuamente, o indivíduo vai-se diferenciando e se igualando de acordo com as inúmeras comunidades de que faz parte, tornando-se uma unidade coesa contraditória, múltipla e inconstante - essa é a importância da cultura que de fato identifica o indivíduo e seu grupo, tornando-os únicos diante dos outros.

\begin{abstract}
Pensar a família como uma realidade que se constitui pelo discurso sobre si próprio, internalizado pelos sujeitos, é uma forma de buscar uma definição que não se antecipe à sua própria realidade, mas que nos permita pensar como ela se constrói, constrói sua noção de si, supondo evidentemente que isto se faz em cultura, dentro, portanto, dos parâmetros coletivos do tempo e do espaço em que vivemos que ordenam as relações de parentesco (entre irmãos, entre pais e filhos, entre marido e mulher). Sabemos que não há realidade humana exterior à cultura, uma vez que os seres humanos se constituem em cultura, portanto, simbolicamente. (SARTI, 2005, p. 27).
\end{abstract}

Convém observar que a psicologia social, por ser uma ciência moderna, também repercute nos aspectos antropológicos da cultura identitária. Assim, tais aspectos podem contribuir decisivamente para o desenvolvimento dos processos humanos, históricos e sociais, além de ajudar na compreensão da estrutura dos povos organizados. Os resultados dos estudos antropológicos auxiliam na superação dos desequilíbrios e tensões culturais, ao passo em que conectam tal campo de investigação à questão contemporânea do hibridismo cultural, por sua vez intrinsecamente ligado à construção da identidade do grupo.

Bons exemplos de dinâmica cultural que emergem de grandes processos de hibridismo podem ser vislumbrados nos movimentos criativos e artísticos, que se proliferam cada dia mais no seio das sociedades contemporâneas. As festas culturais populares, como o Carnaval brasileiro, trazem consigo uma ânsia social de identificação, que diz respeito a tudo que constitui a sociedade: seus modos de produção econômica, suas tecnologias, sua organização política e legal, seus princípios de parentesco, seus códigos de conhecimento, suas crenças religiosas, sua língua e sua psicologia - é essa gama de aspectos antropológicos que forma a cultura identitária, híbrida por natureza.

A riqueza de formas das culturas e suas relações falam bem de perto a cada um de nós, já que convidam a que nos vejamos como seres sociais, nos fazem pensar na natureza dos todos sociais de que fazemos parte, nos fazem 
indagar sobre as razões da realidade social de que partilhamos e das forças que as mantêm e as transformam. Ao trazermos a discussão para tão perto de nós, a questão da cultura torna-se tanto mais concreta quanto adquire novos contornos. Saber se há uma realidade cultural comum à nossa sociedade torna-se uma questão importante. Do mesmo modo evidencia-se a necessidade de relacionar as manifestações e dimensões culturais com diferentes classes e grupos que as constituem. (SANTOS, 2006, p. 54).

Outro fator que influencia o estabelecimento dos processos culturais das sociedades é a comunicação, pois é a partir dela que os grupos humanos podem interagir e trocar informações. O próprio desenvolvimento da linguagem só foi possível devido ao fato de os seres humanos serem possíveis de se comunicar efetivamente. Tal processo, inicialmente, parte da necessidade de cooperação na execução de tarefas básicas de sobrevivência, e desemboca, em última análise, na interação verbal e não-verbal base de construção do conhecimento e da natureza cultural da história humana.

Nesse contexto, o Estado exerce um fundamental papel de responsável pela promoção de uma diversidade cultural que se fundamente em uma cidadania participativa ${ }^{5}$, baseada na igualdade e no diálogo sobre a diversidade. Assim, a máquina estatal adquire poder de ajudar a quebrar preconceitos e estereótipos enraizados e vinculados a práticas etnocêntricas. É necessário que o Estado considere todos os fatores que influenciam essa sintonia de objetivos envolvendo os conflitos locais, a estrutura, o financiamento e a forma como a cultura é administrada.

\begin{abstract}
Há que se pensar num alargamento do conceito de cultura para as propostas acontecerem numa perspectiva intersetorial, ou seja, para que haja articulação entre as diversas políticas públicas da região, de modo a não permanecer a cultura como algo isolado ou suplementar... Um governo que não reconhece e valoriza a pluralidade de seus cidadãos, as diferentes realidades locais e a riqueza cultural presente nos diversos territórios que compõem bairros, cidades ou estados, certamente direciona suas ações a uma pequena parcela da população e favorece a cultura hegemônica que tende a homogeneizar identidades e expressões. (PESTANA, 2011, p. 96).
\end{abstract}

Por fim, a discussão acerca da psicologia social que se entrelaça nos conceitos de cultura e hibridismo deságua na construção do laço que une as subjetividades do grupo social.

\footnotetext{
${ }^{5}$ De acordo com Lev Semyonovich Vygotsky, renomado psicólogo e sociólogo russo, cidadania participativa é o vínculo jurídico-político que, traduzindo a pertença de um indivíduo ao Estado, o define perante este num conjunto específico de direitos e obrigações cuja eficácia só restará positiva se existir colaboração mútua entre eles, na eventual troca de experiências sobre os significados sociais.
} 
Isso porque não há laço natural, visto que as sociedades humanas vivem em um mundo de linguagem. As relações entre as culturas são assim norteadas pelo discurso e se exercitam com margens de liberdade variáveis, fato que ilustra a importância da psicologia social para criação do laço social articulador dos macrocosmos social e individual. Tal união, promovida com critérios reguladores e humanísticos é o que de fato faz com que os indivíduos se conectem e ao mesmo tempo se separem - pois se ampara sobre um vácuo que protegerá a causa do sujeito, que é sua singularidade.

\section{GLOBALIZAÇÃO, CULTURA E PÓS-MODERNIDADE}

É a partir desse cenário híbrido que se deve entender a globalização que surge com o desenvolvimento acelerado dos meios de comunicação. Nota-se que nesse gigantesco campo midiático que surge, os meios de comunicação passam a disseminar estilos de vida tão globalizados que o mundo se observa muito pequeno e as sociedades se sentem cada vez mais próximas umas das outras, não obstante as dificuldades experimentadas nessa aproximação e da busca de identidade cultural em outras comunidades. Apesar disso, haverá sempre espaço para a promoção de relações harmoniosas e amistosas.

Nesse sentido, uma das decorrências da globalização é a miscigenação dos povos causados, no contexto social, pela imigração e emigração. Esta influência cultural intervém em todas os comportamentos sociais e deve ser atentamente administrada para facilitar a readequação, dependendo da situação específica do imigrante ou emigrante, sem maiores transtornos. São estes elementos que estão transformando o sujeito, pois a identidade antes tida como estável está se adaptando rapidamente à fluidez, não por uma única, mas por múltiplas identidades diferentes ${ }^{6}$.

É importante assinalar a relação entre o multiculturalismo e as dinâmicas econômicas e políticas da globalização. Essa relação passa pelo debate sobre a concepção de direitos humanos, sobre a possibilidade de serem concebidos em termos multiculturais, sobre novas concepções de cidadania, de uma cidadania cosmopolita assente no reconhecimento da diferença, e na criação de políticas sociais procurando a redistribuição, a inclusão e a redução das desigualdades... Há que considerar o migrante numa perspectiva

\footnotetext{
${ }^{6}$ Segundo os estudos de Stuart Hall, teórico cultural jamaicano, o sujeito contemporâneo é formado não mais por uma identidade fixa, mas sim por uma identidade de caráter fluido, mutável e continuamente adaptável em relação às formas pelas quais estas identidades são abordadas nos sistemas culturais que os influenciam.
} 
transnacional, com múltiplas relações (familiares, econômicas e sociais), colocando em contato o local e o global, tendo as redes migratórias e a cultura de migração papéis decisivos. (RAMOS, 2013, p. 80).

A pós-modernidade deriva desse novo contexto da falta de identidade que acontece, sobretudo, em virtude do indivíduo não poder mais fazer parte de sua comunidade como um ser pleno, como na compreensão dos iluministas, integrado desde o seu nascimento a até a sua morte, ou ainda, como um ator sociológico, senhor de uma essência que o tornaria único no mundo, mas que poderia ser facilmente transformada quando em contato com outras parcelas do mundo exterior. Atualmente a pós-modernidade surge com uma nova fase de identificação, sendo esse indivíduo pós-moderno, uma pessoa sem identidade rígida, surgido da diversidade de culturas do mundo globalizado, tendo sua identidade construída e reconstruída infindavelmente, por toda sua vida.

Para além disso, tentar refletir sobre como as diferentes sociedades podem ser funcionais sem utilizar alguns conceitos de tempo verbal, pode complicar a pesquisa de qualquer antropólogo desavisado - e nesse campo mora a importância das diferenças geográficas e linguísticas que existem entre os povos. A língua enquanto expressão da mente é o principal motor que faz com que os grupos elaborem seus pensamentos e sistemas culturais. Ao se debruçar sobre uma comunidade de símbolos históricos e sociais, a antropologia pode facilmente observar a relação entre cultura e a língua, e a partir de então, estudar a relação entre psicologia social e cultura híbrida.

Paralelo à globalização, surge a mundialização ${ }^{7}$, que é um processo de alteração da dinâmica social onde ocorrem, de fato, as trocas culturais entre sociedades próximas ou não. Trata-se de um processo que advém da globalização tecnicamente relativa à movimentações econômicas e à descentralização da produção cultural. Na mundialização temos trocas contínuas de elementos históricos e culturais, que podem acontecer ao mesmo tempo ou em tempo desigual, a depender dos níveis de aproximação e conhecimento linguístico.

Um marcante exemplo de movimento cultural híbrido na história brasileira é o Clube da Antropofagia, que juntamente com a Revista da Antropofagia, em que é divulgado o

\footnotetext{
${ }^{7}$ De acordo com René Armand Dreifuss, historiador e cientista político uruguaio, mundialização é um termo que concentra o conjunto de novos padrões de comportamento ético e de convivência entre os cidadãos dentro dos países, que agora se tornariam cada vez menos indivíduos nacionais e cada vez mais cidadãos do mundo. Tudo isso em prol dos novos modos de interação cada vez mais complexos, e tendentes a um futuro de diferentes organizações sociais.
} 
Manifesto Antropófago escrito pelo ensaísta paulista Oswald de Andrade, adaptou a definição eurocêntrica e negativa do ritual canibalístico da antropofagia ${ }^{8}$ como metáfora de um processo decisivo de formação da cultura brasileira, que na esfera da cultura, caracterizou o início de um longo período de assimilação crítica das ideias e modelos europeus nas mais demais formas de cultura artística brasileira.

Há que se cuidar, portanto para não cair na interpretação ligeira da senha antropofágica adotada por Oswald como sinônimo do festival canibalista em que se matava e comia o inimigo por gula ou vingança -, o que reduziria a metáfora antropofágica ao simples ato literário de destruição, quando, na verdade, opera-se nesse ato um processo dialético... O que Oswald quis foi recusar, incorporar e questionar ao mesmo tempo a cultura e os modelos e repertórios literários dominantes, revisando-os e analisando-os criticamente a realidade cultural brasileira. (MALTZ, 1993, p. 11).

Nesse sentido, desafios futuros advindos das relações sociais da contemporaneidade também partem da investigação do papel da internet no contexto social, assim como das experiências que influenciam a difusão de valores e transformam as relações entre as culturas locais e a cultura global. Todavia, positivamente, tais valores acabam por não se limitar ao individualismo e ao consumismo exacerbado - também compõem essa cultura global a democracia, os direitos humanos e as liberdades individuais e coletivas.

Contudo, deve restar destacada a importância do discurso histórico e social sobre a cultura. Esta representação sinaliza novamente, a pressa no reconhecimento e respeito pelas diferenças culturais; a relevância em assegurar a existência e para além disso, a resistência de redutos de tradições que organizam autenticidades culturais, percepções de mundo e identidades socioculturais independentes. Orientar a manutenção da pluralidade cultural e a mitigação de desigualdades sociais parece, absolutamente, caracterizar uma das grandes questões a serem respondidas pela civilização humana, a partir do século XXI.

É um grande paradoxo, pois os povos recebem a cultura global cada um à sua maneira e incorporam-nas também de forma diferente. Todas as culturas, de alguma forma, são alteradas, mas ainda assim há modos de vida que vão, aos poucos, se tornando universalizados, sob a influência da cultura global... 0 diálogo intercultural pode ser visto como uma forma de frear os impactos da

\footnotetext{
${ }^{8}$ Em relação ao Movimento Antropofágico, a obra Antropofagia palimpsesto selvagem, de Ana Beatriz Sampaio Soares Azevedo, aborda a complexidade conceitual, artística e formal articulando a história do Movimento com os diálogos de Oswaldo de Andrade com outros autores e textos.
} 
globalização que são prejudiciais à preservação das culturas, uma vez que ele incentiva parâmetros internacionais mínimos para a proteção dos direitos culturais, entre os mais variados povos, tais como tolerância, democracia, respeito à diversidade e ao pluralismo (SILVA, 2016, p. 25).

A construção da cultura da união é o que se reflete na veemência e rapidez dos fluxos de informações, asseguradas pelo desenvolvimento tecnológico dos meios de comunicação, e que exercem função primordial na revelação da existência de múltiplas culturas. A pósmodernidade leva indivíduos e grupos a se depararem com diversas culturas, e é tal processo que, circunstancialmente, leva ao aparecimento de outras culturas - o que tende a provocar, ainda, uma condescendência cada vez maior à diversidade, em resistência aos eventuais processos de negação da identidade social.

\section{CONSIDERAÇÕES FINAIS}

Na retomada do objeto de análise desta pesquisa, têm-se que o paradoxo investigado na relação entre hibridismo e cultura na pós-modernidade, vislumbra a defesa da diversidade, ao passo em que pode dificultar o desenvolvimento da identidade individual e social. Todavia, esse paradoxo não deve, em momento algum, refletir-se em mera parcimônia quando o assunto passa a ser a relação etnocentrista que eventualmente se constrói entre duas ou mais culturas. É preciso, para compreensão global do fenômeno, analisar o hibridismo, a psicologia social e a globalização envolvidas nesse contexto.

Em relação ao hibridismo cultural, é fundamental que as sociedades possam entender seu papel social no mundo histórico, saber de suas capacidades e reconhecer seus mecanismos culturais e linguísticos, de modo a se orgulhar de tal sistema cultural. Contudo, tal reconhecimento não pode dar lugar a um sentimento estrutural de resistência ao que se apresenta novo e diferente, pois sem tal conexão muitos dos grupos sociais não chegariam a se conhecer e se desenvolver completamente ${ }^{9}$, ao passo em que é nesse campo onde mora o perigo da congregação de ideias elitistas, preconceituosas e muitas vezes, racistas.

\footnotetext{
${ }^{9} \mathrm{Na}$ obra Culturas híbridas - estratégias para entrar e sair da modernidade, importante texto de Néstor García Canclini, esse tema é abordado sob o espectro da inovação e democratização, discutindo as relações entre a modernidade e a democratização do acesso à cultura na América Latina.
} 
Outro ponto de nevrálgica importância para a compreensão da cultura contemporânea é a questão da psicologia social, que historicamente contribui para o desenvolvimento dos processos por que passam os grupos sociais, a partir de uma análise que dá ênfase à psique e ao comportamento social dos indivíduos, quando no interior de uma cultura específica e quando adentra ou recepciona outra diferente. Como exemplo de um processo social, a psicologia, ciência que bebe da fonte da antropologia cultural se torna cada dia mais central no contexto de estudo das culturas das sociedades modernas.

No que tange a globalização, observa-se que no mundo contemporâneo não existe mais a possibilidade de se desenvolver uma cultura pura de significados latentes de simbolismo identitário uno. Surge assim, a necessidade de construir pontes de convivência e trocas de experiências fundamentadas em um contexto pós-moderno, impossível de retroceder, que dê conta de relacionar e transformar, de fato, duas culturas antes distantes, em duas culturas conectadas, ao ponto de serem capazes de coexistir sem conflitos - esse é o desafio que se apresenta no mundo contemporâneo.

Contemporaneamente, outra questão que adentra o campo de análise dos processos culturais é a agenda das guerras identitária que se disseminaram junto à pós-modernidade. Assim, quaisquer reflexões acerca de tais processos identitários implica em uma descrição das relações de poder que abrangem pontos basilares tornados importantes como definidores de aspectos da diferença. É preciso, nesse contexto, entender as identidades como relacionais, investigar as inseguranças dos processos sociais que acabam por fundar ou mesmo refundar modelos arcaicos de subordinação e hierarquização e estudar os mecanismos de inserção social de agentes sociais em contextos regionais. Ademais, o ideal é que essa estrutura de reflexão se fundamente em um sistema de mediação de conflitos caracterizado pela descentralização dos aspectos antropológicos.

Por fim, este trabalho evidencia a importância dos estudos culturais sobre hibridismo na contemporaneidade - que se firma na disseminação, cada vez maior, de movimentos sociais dinâmicos, livres para extrapolar o que se esperava de grupos culturais préglobalização - contudo, não se pretende esgotar aqui todas as vertentes com as quais esse campo de estudo pode ser analisado, pois continuamente os processos culturais têm criado novos sentidos e espaços para suas próprias atuações frente às identidades das diversas 
sociedades. Aliás, é essa expansão que garante, em ato contínuo, a abertura de novas tendências artísticas, culturais e humanas a serem estudadas.

REFERÊNCIAS

ANDRADE, O. de. O manifesto antropófago. In: TELES, G. M. Vanguarda européia e modernismo brasileiro: apresentação e crítica dos principais manifestos vanguardistas. 3a ed. Petrópolis: Vozes; Brasília: INL, 1976.

AZEVEDO, A. B. S. S. Antropofagia palimpsesto selvagem. São Paulo: Cosac Naify, 2016.

CAMPOS, L. e CANAVEZES, S. Introdução à Globalização. Lisboa: Centro de Formação e de Inovação Tecnológica - CGTP, Instituto Bento Jesus Caraça, pgs. 75-76, 2007.

CANCLINI, N. G. Culturas híbridas - estratégias para entrar e sair da modernidade. São Paulo: Editora da Universidade de São Paulo - USP, 1997.

CARDOSO, D. et al. Espacialidade e ressonâncias do patrimônio cultural: reflexões sobre identidade e pertencimento. Revista de Geografia e Ordenamento, n. 11, jun. 2017, p. 83-98., Disponível em: http://www.scielo.mec.pt/pdf/got/n11/n11a05.pdf. Acesso em: set. de 2019.

DAVIES, L. F.; NUNES, D. S. et al. A importância do reconhecimento da diversidade cultural face ao processo de homogeneização da globalização. XII Seminário Internacional de Demandas Sociais e Políticas Públicas na Sociedade Contemporânea, UNISC, pgs. 5, 2015. Disponível em: https://online.unisc.br/acadnet/anais/index.php/sidspp/article/view/13108/2301. Acesso em: set. de 2019.

DREIFUSS, R. A. A época das perplexidades. Mundialização, Globalização e Planetarização: novos desafios. Petrópolis: Vozes, 1996.

IORIS, R. R. A globalização cultural e os desafios para uma governança global democrática. Revista Mural Internacional, n. 1, jan./jun. 2010. p. 33-39.

GUEIROS, D. A. Família e trabalho social: intervenções no âmbito do serviço social. Revista Katálysis, n. 1, jan./jun. 2010. p. 126-132. Disponível em: http://www.scielo.br/pdf/rk/v13n1/15.pdf. Acesso em: ago. de 2019.

HALL, S. A Identidade Cultural da Pós-Modernidade. Rio de Janeiro: Editora DP\&A, 2002.

HERSKOVITS, M. J. The negro in Bahia, Brazil: a problem in method. Bellefontaine: American Sociological Review, 1943. p. 394-402.

MALTZ, B. Antropofagia: rito, metáfora e pau-brasil. In: FERREIRA, S; MALTZ, B. e TEIXEIRA, J. Antropofagia e tropicalismo. Porto Alegre: Editora UFRGS, 1993. 
PESTANA, A. B. Cultura como prática de cidadania: uma perspectiva ampliada do conceito. Serviço Social em Revista, n. 2, jan./jun. 2011. p. 85-103. Disponível em: http://www.uel.br/revistas/uel/index.php/ssrevista/article/view/7779/9109. Acesso em: agosto de 2019.

RAMOS, M. da C. P. Globalização e Multiculturalismo. Revista Inter-Legere, n. 13, jul./dez. 2013. P. 75-101

ROCHA, E. P. G. O que é etnocentrismo. São Paulo: Brasiliense, 1994.

SANTOS, J.L. dos. O que é cultura. São Paulo: Brasiliense, 2006.

SARTI, C. A. A familia como espelho: um estudo sobre a moral dos pobres. Campinas: Autores Associados, 1996.

SEIXAS, R. Identidade cultural da América Latina: conflitos culturais globais e mediação simbólica. Brazilian Journal of Latin American Studies, ano 8, vol. 1, 2008. p. 93-120. Disponível em: http://www.revistas.usp.br/prolam/article/view/82312/85285. Acesso em: set. de 2019.

SILVA, C. R. V. A influência da globalização nas manifestações culturais e o diálogo intercultural como uma genuína alternativa de respeito à diversidade e ao multiculturalismo. Anuário Brasileiro de Direito Internacional, Corte Interamericana de Direitos Humanos, Organização dos Estados Americanos - OEA, 2016. p. 19-35

VIGOTSKI, L. S. A construção do pensamento e da linguagem. São Paulo: Martins Fontes, 2000.

Recebido em 22 de maio de 2020.

Aprovado em 04 de outubro de 2020

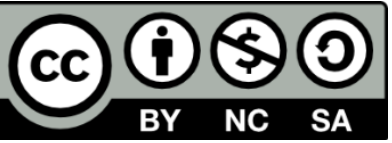

